\title{
Are Myocardium Deformation Indices Influenced by Cardiac Load, Age or Body Mass Index?
}

\author{
Vera Maria Cury Salemi ${ }^{\circledR}$ and Marcelo Dantas Tavares de Melo ${ }^{2}$ \\ Instituto do Coração (InCor) do Hospital das Clinicas da Faculdade de Medicina da Universidade de São Paulo, ${ }^{1}$ São Paulo, SP - Brazil \\ Universidade Federal da Paraíba, ${ }^{2}$ João Pessoa, PB - Brazil \\ Short Editorial related to the article: Strain Analysis of Left Ventricular Function in the Association of Hypertrophic Cardiomyopathy and \\ Systemic Arterial Hypertension
}

The typical findings of myocardium deformation indices (MDI) in many cardiac diseases, the low cost of the echocardiographic exam, the large availability, the vast implementation of this tool for clinical practice and the prognostic value has allowed the detection of earlier myocardium dysfunction than the traditional measurement of left ventricular (LV) ejection fraction. ${ }^{1}$ Moreover, there are typical MDI patterns in different forms of hypertrophy: decreased values in septum MDI in hypertrophic cardiomyopathy (HCM) or where hypertrophy is more accentuated, or a segmental decrease in mutation carriers in a pre-clinical phase of disease, before development of hypertrophy; ${ }^{2}$ apical sparing in amyloidosis; ${ }^{3}$ striped pattern of myocardium deformation in glycogen storage cardiomyopathy (PRKAG2); ${ }^{4}$ and decrease in subepicardial longitudinal strain in Anderson-Fabry disease. ${ }^{5}$ In hypertension with concentric and eccentric hypertrophy, the MDI patterns are related to different geometric patterns, ${ }^{6}$ but they are frequently preserved in athletes. ${ }^{4}$

The question whether MDI would be reliable in different machines and vendors was demonstrated that the accuracy of these indices were better than conventional echocardiography measurements and they are reliable for daily echocardiographic practice. ${ }^{7}$

The paper published in the same issue of this journal showed that the authors evaluated the LV global longitudinal strain in 45 patients divided into 2 groups: with HCM and the association with hypertension with $\mathrm{HCM}$, and showed that strain was decreased in the latter group compared to the first one. ${ }^{8}$ It is noticeable the difference between both groups about their age, body mass index (BMI) and blood pressure. Besides, many studies have demonstrated that global longitudinal strain could be affected by those variables mentioned, as demonstrated in a paper of 266 healthy subjects, $39.2 \pm 17.5$ years, 137 women, submitted to transthoracic echocardiography evaluation and showed that global longitudinal strain was progressively reduced with increasing age decades. ${ }^{9}$ Metabolic syndrome may also play a role in myocardial deformation showed in a study of 384 patients grouped according to BMI (normal weight $<25 \mathrm{~kg} / \mathrm{m}^{2}$,

\section{Keywords}

Echocardiography/methods; Myocardium Deformation; Hypertension; Heart Failure; Strain; Hypertrophic Cardiomyopathy.

Mailing Address: Vera Maria Cury Salemi •

Av. Jandira, 185 ap 41B. Postal Code 04080-000, São Paulo, SP - Brazil E-mail: verasalemi@cardiol.br, verasalemi@uol.com.br

DOI: 10.5935/abc.20190211 overweight $25-29 \mathrm{~kg} / \mathrm{m}^{2}$, and obesity $\geq 30 \mathrm{~kg} / \mathrm{m}^{2}$ ), compared to healthy control group. Regardless of the presence or not of diabetes, overweight and obesity impair LV ejection fraction and global longitudinal strain. ${ }^{10}$ Interestingly, Russell et al. ${ }^{11}$ were the first to describe a new method that evaluated myocardial work using a non-invasive pressure-strain loop by echocardiogram. ${ }^{11}$ In a canine model, it was demonstrated a significant reduction in LV strain after aortic construction. On the other hand, LV pressure-strain loop area did not change, which means that myocardial work seems to be not affected by increasing the afterload, but global longitudinal strain could transient change by hemodynamics status. ${ }^{12}$ Therefore, we could be more precautious when we stratify the same cardiomyopathy simply by using global longitudinal strain, not considering afterload importance. Furthermore, the previous study compared 80 hypertensive patients, $80 \mathrm{HCM}$ patients and 80 controls showed that longitudinal strain was lower in HCM patients, and also, the best parameter to differentiate both diseases was the MDI ratio of endocardium and epicardium layers. However, this parameter was not evaluated in the present study. ${ }^{13}$

The LV outflow tract obstruction is defined as peak LV gradient greater than or equal to $30 \mathrm{mmHg}$ at rest or with provocation, is present in approximately two-thirds of patients with hypertrophic cardiomyopathy. ${ }^{14}$ This dynamic obstruction leads to an increase in left ventricle afterload which could impair the global longitudinal strain itself, as previous mentioned. However, the authors of this present study did not mention this feature which certainly affects the myocardial deformation. The myocardial thickness and mainly, the presence of fibrosis affect negatively the patients' prognosis. Both parameters were not described in this present study and it is well known that they are related to a LV global longitudinal strain reduction. ${ }^{15}$ When myocardial work was analyzed in hypertrophic cardiomyopathy subjects, one variable called global constructive work was the only predictor of LV fibrosis at multivariable analysis (OR 1.01, 95\% Cl: $0.99-1.08, p=0.04) .{ }^{16}$ A cutoff value of 1623 mmHg\% (AUC 0.80, 95\% Cl: 0.66-0.93, p < 0.0001) was able to predict myocardial fibrosis with good sensitivity and fair specificity (82\% and $67 \%$, respectively).

In conclusion, MDI are an important tool helping to distinguish HCM from other cardiomyopathies, as well as, they present value for risk stratification impact. However, it is extremely recommended to take into account the hemodynamic status whenever analyze MDI data. Moreover, it is a diagnostic challenge the presence of overlapping of hypertrophic cardiomyopathy and hypertension. Myocardial work may play a role to solve this. 


\section{Short Editorial}

\section{References}

1. Badano LP, Kolias TJ, Muraru D, Abraham TP, Aurigemma G, Edvardsen T, et al. Industry representatives; Reviewers: This document was reviewed by members of the 2016-2018 EACVI Scientific Documents Committee. Standardization of left atrial, right ventricular, and right atrial deformation imaging using two-dimensional speckle tracking echocardiography: a consensus document of the EACVI/ASE/Industry Task Force to standardize deformation imaging. Eur Heart J Cardiovasc Imaging. 2018;19(6):591-600.

2. Baudry G, Mansencal N, Reynaud A, Richard P, Dubourg O, Komajda M, et al. Global and regional echocardiographic strain to assess the early phase of hypertrophic cardiomyopathy due to sarcomeric mutations. Eur Heart J Cardiovasc Imaging. 2019, jez084 [Internet] [Cited in 2019 july 23]. Available from: https://doi.org/10.1093/ejhci/jez084

3. Pradel S, Magne J, Jaccard A, Fadel BM, Boulogne C, Salemi VMC, et al. Left ventricular assessment in patients with systemic light chain amyloidosis: a 3-dimensional speckle tracking transthoracic echocardiographic study. Int J Cardiovasc Imaging. 2019;35(5):845-54.

4. Pena JLB, Santos WC, Araújo SA, Dias GM, Sternick EB. How Echocardiographic Deformation Indices Can Distinguish Different Types of Left Ventricular Hypertrophy. Arq Bras Cardiol. 2018;111(5):758-9.

5. Esposito R, Santoro C, Sorrentino R, Riccio E, Citro R, Buonauro A, et al. Anderson-Fabry Federico II Naples, ITalY (AFFINIITY) Group. Layer-specific longitudinal strain in Anderson-Fabry disease at diagnosis: A speckle tracking echocardiography analysis. Echocardiography. 2019;36(7):1273-81.

6. Xu TY, Yang Y, Li JJ, Li Y, Wang JG. Left ventricular deformation in relation to the geometric pattern in hypertensive patients. Medicine (Baltimore). 2019;98(4):e14257.

7. Ünlü S, Mirea O, Duchenne J, Pagourelias ED, Bézy S, Thomas JD, et al. Comparison of Feasibility, Accuracy, and Reproducibility of Layer-Specific Global Longitudinal Strain Measurements Among Five Different Vendors: A Report from the EACVI-ASE Strain Standardization Task Force. J Am Soc Echocardiogr. 2018;31(3):374-80.
8. Gil TCP, Castier MB, Gondar AFP, ales AF, Santos MO, de Lima FCS, et al. Strain analysis of left ventricular function in the association of hypertrophic cardiomyopathy and systemic arterial hypertension. Arq Bras Cardiol. 2019; 113(4):677-684.

9. Alcidi GM, Esposito R, Evola V, Santoro C, Lembo M, Sorrentino R, et al. Normal reference values of multilayer longitudinal strain according to age decades in a healthy population: A single-centre experience. Eur Heart J Cardiovasc Imaging. 2018;19(12):1390-6.

10. Blomstrand P, Sjöblom P, Nilsson M, Wijkman M, Engvall M, Länne T, et al. Overweight and obesity impair left ventricular systolic function as measured by left ventricular ejection fraction and global longitudinal strain. Cardiovasc Diabetol. 2018;17(1):113.

11. Russell K, Eriksen M, Aaberge L, Wilhelmsen N, Skulstad H, Remme EW, et al. A novel clinical method for quantification of regional left ventricular pressure-strain loop area: a non-invasive index of myocardial work. Eur Heart J. 2012;33(6):724-33.

12. Boe E, Russell K, Eek C, Eriksen M, Remme EW, Smiseth OA, et al. Noninvasive myocardial work index identifies acute coronary occlusion in patients with non-ST-segment elevation-acute coronary syndrome. Eur Heart J Cardiovasc Imaging. 2015;16(11):1247-55.

13. Sun JP, Xu TY, Ni XD, Yang XS, Hu JL, Wang SC, et al. Echocardiographic strain in hypertrophic cardiomyopathy and hypertensive left ventricular hypertrophy. Echocardiography. 2019;36(2):257-65.

14. Veselka J, Anavekar NS, Charron P. Hypertrophic obstructive cardiomyopathy. Lancet. 2017;389(10075):1253-67.

15. Haland TF, Almaas VM, Hasselberg NE, SaberniakJ, Leren IS, Hopp E, et al. Strain echocardiography is related to fibrosis and ventricular arrhythmias in hypertrophic cardiomyopathy. Eur Heart J Cardiovasc Imaging. 2016;17(6):613-21.

16. Galli E, Vitel E, Schnell F, Le Rolle V, Hubert A, Lederlin M, et al. Myocardial constructive work is impaired in hypertrophic cardiomyopathy and predicts left ventricular fibrosis. Echocardiography. 2019;36(1):74-82. 